\title{
Fault characteristics of Inverter-Interfaced Distributed Generation
}

\author{
Xiaoqin $\mathrm{Ma}^{1, *}$, Hui Lv${ }^{1}$, and Wenjuan Xiao ${ }^{1}$ \\ ${ }^{1}$ Northwest Minzu University, 730030, No.1 northwest new village, Lanzhou City, Gansu Province, China
}

\begin{abstract}
Distributed generations can be divided into traditional synchronous generators and inverter interfaced distributed generations (IIDG) according to their different operation mode. While the fault characteristics of IIDG is different from traditional Distributed Generators, the in-depth analysis on output characteristics and fault characteristics of IIDG are the foundation of micro grid protection. The mathematical models under $\mathrm{P} / \mathrm{Q}$ and $\mathrm{V} / \mathrm{F}$ control strategy are discussed. After simplifying its model, the fault characteristics of IIDG under P/Q and V/F control strategy are studied using the simulation of PSCAD/EMTDC. The analysis on the fault characteristics of IIDG that lays the theoretical foundation for the micro-grid relay protection.
\end{abstract}

\section{Introduction}

As a key technology in smart grid, distributed power supply technology has attracted more attention ${ }^{[1]}$. With the rapid development of power electronics technology, inverter interfaced distributed generation (IIDG) has been widely used ${ }^{[2]}$. The research on traditional rotating distributed generation (DG) is relatively mature for the time being, while limited research has been conducted on IIDG. Therefore, it is necessary to analyze IIDG and its fault output characteristics for the distribution network protection $^{[3,4]}$.

\section{Modelling of IIDG}

In order to study the fault characteristics of IIDG, it is necessary to simplify its model reasonably. Firstly, there is always a capacitor on the bus in front of the DC side of the IIDG, the existence of this energy storage device makes the output voltage of the IIDG DC side basically constant; Secondly, the capacitor between the IIDG inverter and its DC side can maintain the output voltage of IIDG and also provide energy for the IIDG in the transient state; Finally, environmental factors such as illumination and wind speed can be considered as invariable in tens of milliseconds of power system relay protection action, so the impact of environmental factors on IIDG can be ignored. Therefore, in the process of IIDG transient analysis, DC source can be approximately used to replace the output of IIDG DC side without loss of generality ${ }^{[5]}$.

The simplified IIDG model is shown in Fig.1. It can be seen from the figure that the transient characteristics of IIDG mainly depend on the control strategy of the inverter, other factors can be ignored.

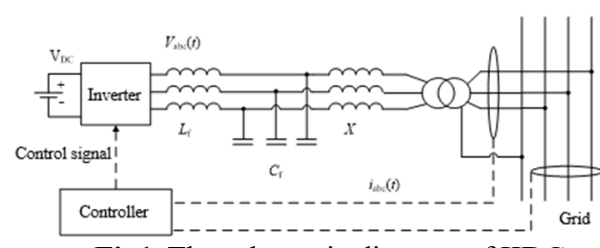

Fig1. The schematic diagram of IIDG

This shows that the influence of the control strategy of IIDG inverter on its fault characteristics is more important. Therefore, the mathematical model of IIDG is established respectively under $\mathrm{P} / \mathrm{Q}$ and $\mathrm{V} / \mathrm{F}$ control strategy.

\subsection{Interface model of IIDG under P/Q control}

When the inverter adopts $\mathrm{P} / \mathrm{Q}$ control strategy, that is, the controller in Figure 1 adopts $\mathrm{P} / \mathrm{Q}$ control strategy, its control links mainly include three parts, namely power control link, PI control link and limiting control link. The specific control process is shown in Fig.2.

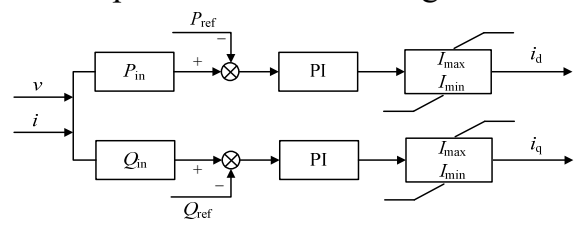

Fig2. P/Q control strategy

The calculation formula of power is:

$$
\begin{aligned}
& P_{\text {in }}=v_{\mathrm{d}} i_{\mathrm{d}}+v_{\mathrm{q}} i_{\mathrm{q}} \\
& Q_{\text {in }}=v_{\mathrm{d}} i_{\mathrm{q}}-v_{\mathrm{q}} i_{\mathrm{d}}
\end{aligned}
$$

The PI control formula is:

$$
\begin{aligned}
& i_{\mathrm{dr}}=\left(k_{\mathrm{p}}+\frac{1}{\mathrm{~s} T_{\mathrm{p}}}\right) \Delta p \\
& i_{\mathrm{qr}}=\left(k_{\mathrm{q}}+\frac{1}{\mathrm{~s} T_{\mathrm{q}}}\right) \Delta q
\end{aligned}
$$




\subsection{Interface model of IIDG under V/F control}

When the inverter adopts $\mathrm{V} / \mathrm{F}$ control strategy, its control links mainly include four parts, power control link, drop control link, PI control link and integral control link, the specific control process is shown in Fig.3.

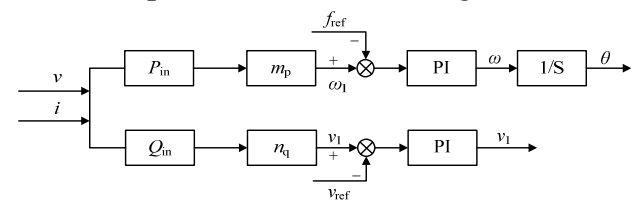

Fig3. V/F control strategy

The power calculation process is the same as that of $\mathrm{P} / \mathrm{Q}$ control.

The drop control formula is:

$\omega_{1}=\omega_{n}-m_{\mathrm{p}} p$

$v_{1}=v_{n}-n_{\mathrm{q}} q$

Where $m_{\mathrm{p}}$ is the slope of active power droop curve, $n_{\mathrm{q}}$ is the slope of reactive power droop curve.

\section{Characteristic analysis for IIDG}

Since the control strategy of the inverter is the main factor affecting the transient characteristics of IIDG, it is necessary to analyze the fault characteristics of IIDG under different control strategies ${ }^{[6]}$. In addition, since DG has two operation modes, independent DG generally adopts $\mathrm{V} / \mathrm{F}$ control strategy to maintain the stability of microgrid frequency and voltage, while grid connected DG usually adopts P/Q control strategy ${ }^{[7,8]}$. Therefore, this section mainly analyzes the fault characteristics of IIDG under $\mathrm{P} / \mathrm{Q}$ control and $\mathrm{V} / \mathrm{F}$ control strategy in the power system transient simulation software PSCAD /EMTDC without considering the protection of inverter and IIDG itself.

\subsection{Simulation analysis on fault characteristics of IIDG under P/Q control strategy}

The simulation model is established under PSCAD, as shown in Fig. 4. At this time, IIDG adopts $\mathrm{P} / \mathrm{Q}$ control strategy for grid connected operation.

The P / Q control parameters are $k_{\mathrm{p}}=1, k_{\mathrm{q}}=1, T_{\mathrm{p}}=0.4$, $T_{\mathrm{q}}=0.5, I_{\max }=1, I_{\min }=-1$. The voltage of the line is $380 \mathrm{~V}$ and the length of the line is $0.2 \mathrm{~km}$, the parameters of the line are $\quad R=0.797 \Omega / \mathrm{km}, \quad X=0.105 \Omega / \mathrm{km}$. The fault characteristics of IIDG under P / Q control strategy are obtained by simulation analysis of various short-circuit faults in transmission lines under P / Q control strategy.

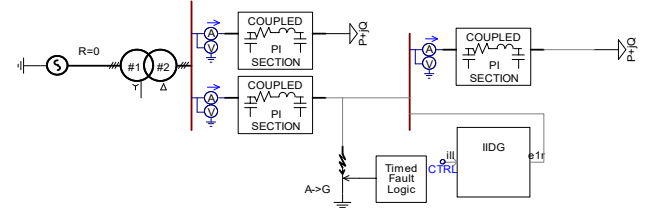

Fig4. The simulation model under $\mathrm{P} / \mathrm{Q}$ control strategy

\subsubsection{Three-phase short circuit fault}

When the three-phase short circuit fault occurs at $50 \%$ of the line, the output current, active power and terminal voltage waveform of the fault phase of the IIDG inverter under P/Q control strategy are shown in Fig. 5.

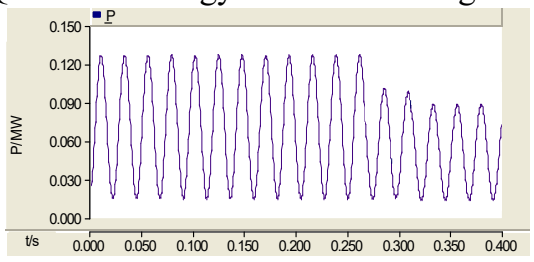

(a) active power waveform

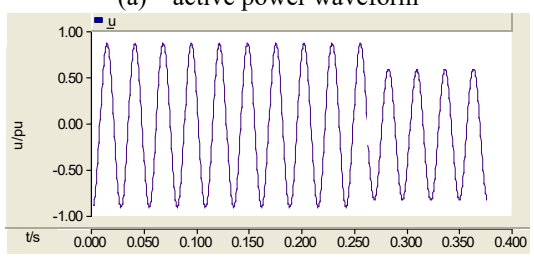

(b) terminal voltage waveform

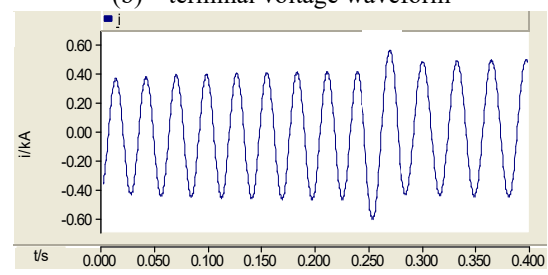

(c) output current waveform

Fig5. Waveforms of $\mathrm{P} / \mathrm{Q}$ controlled inverter when three-phase short circuit fault occurred

This shows the voltage and output active power of IIDG after fault are significantly reduced compared with normal operation. It can be seen from the figure that the instantaneous maximum fault current is about 1.3 times of that under normal operation.

\subsubsection{Two-phase short circuit fault}

When the two-phase short circuit fault occurs at $50 \%$ of the line, the output current, active power and terminal voltage waveform of the fault phase of the IIDG inverter under P/Q control strategy are shown in Fig. 6.

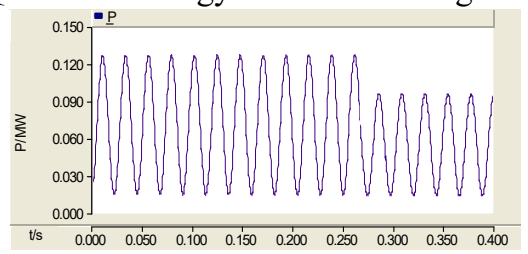

(a) active power waveform

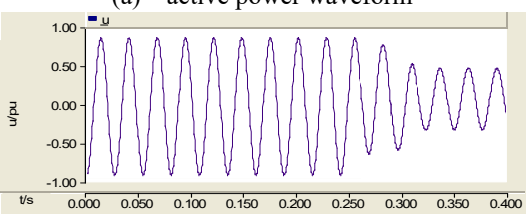

(b) terminal voltage waveform

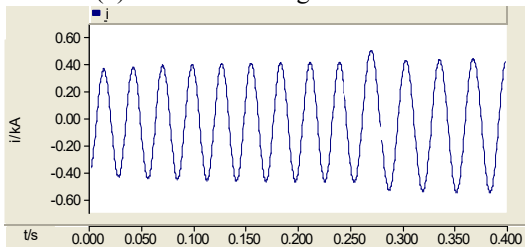

(c) output current waveform

Fig6. Waveforms of $\mathrm{P} / \mathrm{Q}$ controlled inverter when two-phase short circuit fault occurred

At this time, the output power of the fault phase of the IIDG inverter decreases slightly, and the terminal voltage 
drops greatly. The fault current is about 1.3 times of the normal operation current.

\subsubsection{Two-phase grounding short circuit fault}

When two-phase grounding short circuit fault occurs at 50\% of the line, the output current, active power and terminal voltage waveform of the fault phase of the IIDG inverter under P/Q control strategy are shown in Fig. 7.

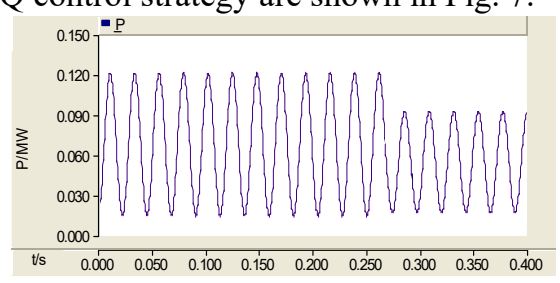

(a) active power waveform

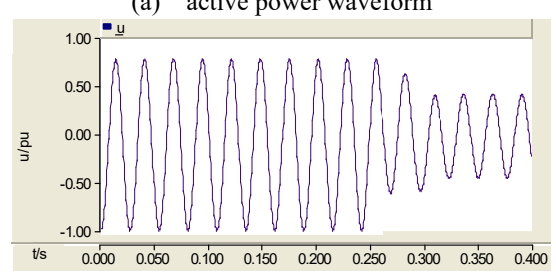

(b) terminal voltage waveform

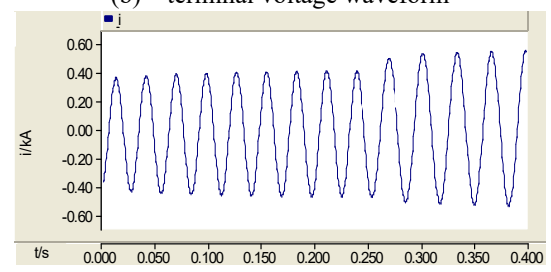

(c) output current waveform

Fig7. Waveforms of $\mathrm{P} / \mathrm{Q}$ controlled inverter when two-phase grounding short circuit fault occurred

At this time, the output power and terminal voltage of the fault phase of the IIDG inverter decreases greatly. The fault current is about 1.5 times of the normal operation current.

\subsubsection{Single-phase grounding short circuit fault}

When single-phase grounding short circuit fault occurs at $50 \%$ of the line, the output current, active power and terminal voltage waveform of the fault phase of the IIDG inverter under $\mathrm{P} / \mathrm{Q}$ control strategy are shown in Fig. 8.

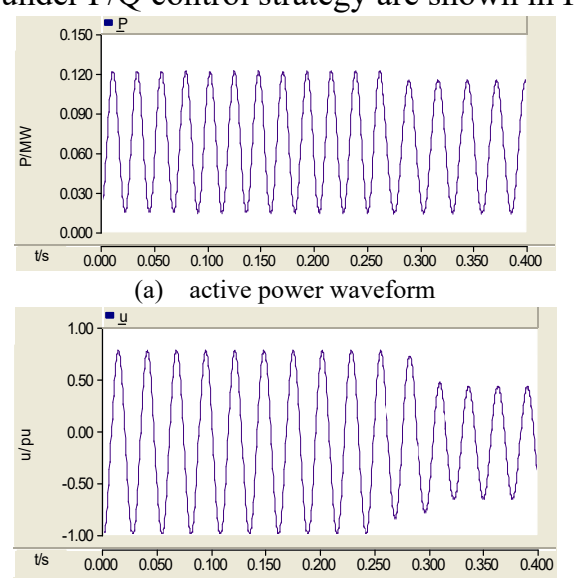

(b) terminal voltage waveform

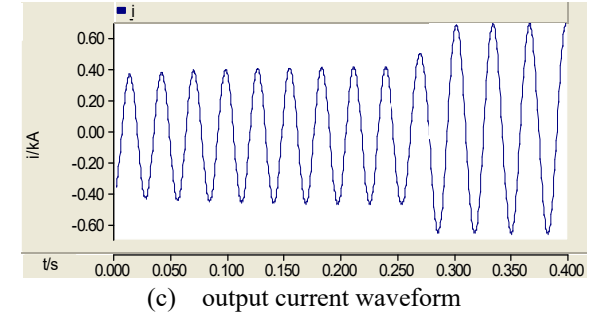

Fig8. Waveforms of $\mathrm{P} / \mathrm{Q}$ controlled inverter when single phase grounding short circuit fault occurred

At this time, the output power of the fault phase of the IIDG inverter is not changed basically, and the terminal voltage decreases slightly, the fault current is about 1.5 times of the normal operation current.

According to the simulation analysis, the fault characteristics data of IIDG under P/Q control strategy are shown in Table 1.

Table1. Normal and fault data under $\mathrm{P} / \mathrm{Q}$ controlled inverter

\begin{tabular}{|c|c|c|c|}
\hline & $\begin{array}{c}\mathrm{P} \\
(\mathrm{MW})\end{array}$ & $\begin{array}{c}\mathrm{U} \\
(\mathrm{pu})\end{array}$ & $\begin{array}{c}\mathrm{I} \\
(\mathrm{kA})\end{array}$ \\
\hline $\begin{array}{c}\text { Normal } \\
\text { operation }\end{array}$ & 0.13 & 1.0 & 0.40 \\
\hline $\begin{array}{c}\text { Three-phase } \\
\text { short circuit }\end{array}$ & 0.08 & 0.42 & 0.62 \\
\hline $\begin{array}{c}\text { Two-phase } \\
\text { short circuit }\end{array}$ & 0.09 & 0.51 & 0.51 \\
\hline $\begin{array}{c}\text { Two-phase } \\
\text { grounding } \\
\text { short circuit }\end{array}$ & 0.09 & 0.49 & 0.62 \\
\hline $\begin{array}{c}\text { Single-phase } \\
\text { grounding } \\
\text { short circuit }\end{array}$ & 0.11 & 0.52 & 0.72 \\
\hline
\end{tabular}

It can be seen from Table 1 that the maximum fault current generated by IIDG is about 1.74 times of rated load current in case of single-phase grounding short-circuit fault, and the minimum fault current generated by IIDG under two-phase short-circuit is about 1.24 times of rated load current, indicating that the zero sequence impedance of IIDG is less than its positive sequence impedance.

The terminal voltage of IIDG decreases the least when single-phase grounding short circuit occurs, which is 0.52 times of the rated voltage; the terminal voltage of IIDG decreases the most when the three-phase short circuit occurs, which is 0.42 times of the rated voltage. This shows that the closer the fault point is to the IIDG, the greater the influence on the terminal voltage is, and the output power is reduced compared with the normal value. At this time, the output power of IIDG cannot maintain the setting value.

To sum up, the terminal voltage of IIDG under P/Q control strategy will decrease when its adjacent feeders are short circuited, so the output active power of IIDG will be affected, which is lower than the rated value. The output fault current of IIDG is not only affected by the maximum allowable current of internal power electronic devices, but also closely related to the output power and voltage of IIDG. 


\subsection{Simulation analysis on fault characteristics of IIDG under V/F control strategy}

The simulation model is established under PSCAD, as shown in Fig. 9. IIDG with V/F control strategy and synchronous generator with active power output of $0.01 \mathrm{MW}$ are the two power sources of the system.

The V / F control parameters are $k_{\mathrm{p}}=1, k q=1, T p=10$, $T q=10, m p=0.001, n q=0.001$.

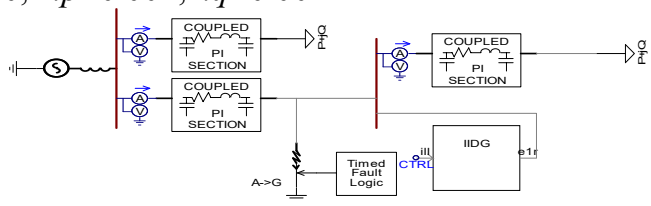

Fig9. The simulation model under V/F control strategy

\subsubsection{Three-phase short circuit fault}

When the three-phase short circuit fault occurs at $50 \%$ of the line, the output current, active power and terminal voltage waveform of the fault phase of the IIDG inverter under V/F control strategy are shown in Fig. 10.

The voltage and output active power of IIDG after fault are significantly reduced compared with normal operation. It can be seen from the figure that the instantaneous maximum fault current is about 1.3 times of that under normal operation.

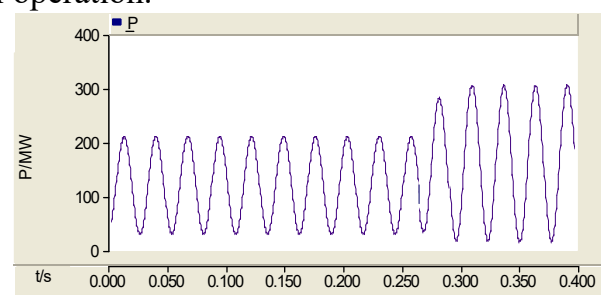

(a) active power waveform

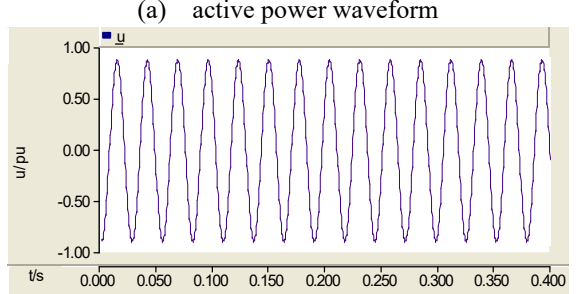

(b) terminal voltage waveform

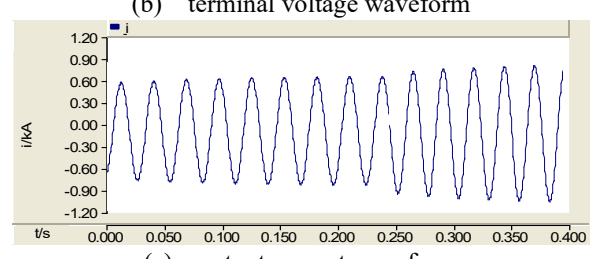

(c) output current waveform

Fig10. Waveforms of V/F controlled inverter when three-phase short circuit fault occurred

It can be seen from Fig. 10 that the terminal voltage of IIDG is basically unchanged at this time.

\subsubsection{Two-phase short circuit fault}

When the two-phase short circuit fault occurs at $50 \%$ of the line, the output current, active power and terminal voltage waveform of the fault phase of the IIDG inverter under V/F control strategy are shown in Fig.11.

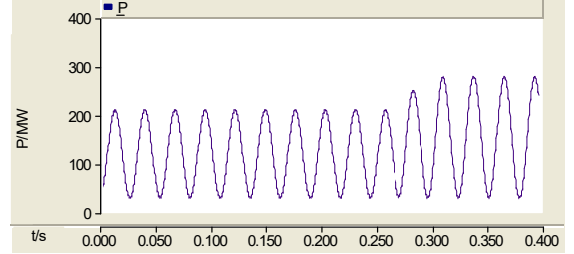

(a) active power waveform

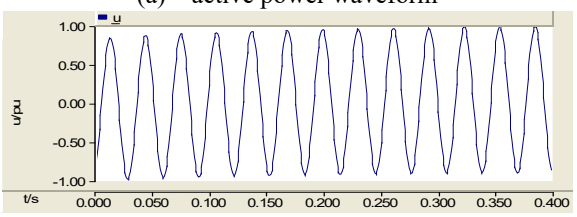

(b) terminal voltage waveform

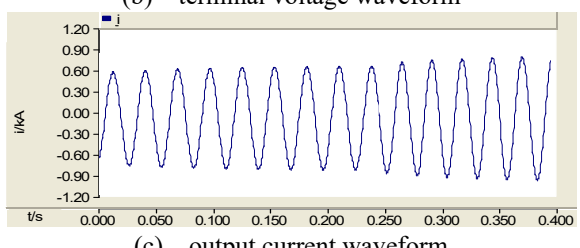

(c) output current waveform

Fig11. Waveforms of V/F controlled inverter when two-phase short circuit fault occurred

It can be seen from Fig. 11 that the terminal voltage of IIDG is basically unchanged at this time.

\subsubsection{Two-phase grounding short circuit fault}

When two-phase grounding short circuit fault occurs at 50\% of the line, the output current, active power and terminal voltage waveform of the fault phase of the IIDG inverter under V/F control strategy are shown in Fig. 12.

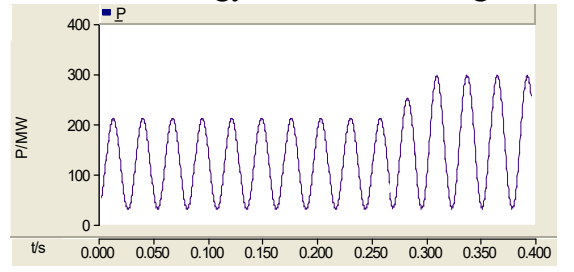

(a) active power waveform

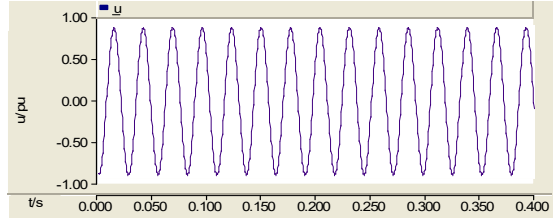

(b) terminal voltage waveform

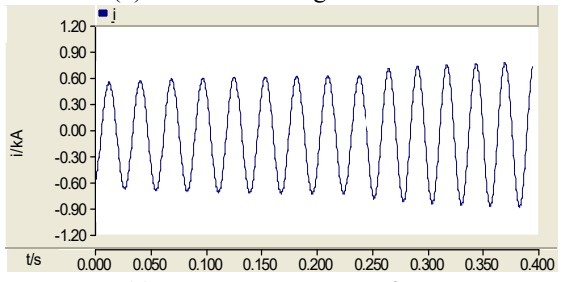

(c) output current waveform

Fig12. Waveforms of V/F controlled inverter when two-phase grounding short circuit fault occurred

It can be seen from Fig.12 that the strategy of V/F control has excellent performance.

\subsubsection{Single-phase grounding short circuit fault}

When single-phase grounding short circuit fault occurs at $50 \%$ of the line, the output current, active power and terminal voltage waveform of the fault phase of the IIDG 
inverter under $\mathrm{V} / \mathrm{F}$ control strategy are shown in Fig. 13. It can be seen from Fig.13 that the strategy of $\mathrm{V} / \mathrm{F}$ control play a good role in maintaining terminal voltage of IIDG stability.

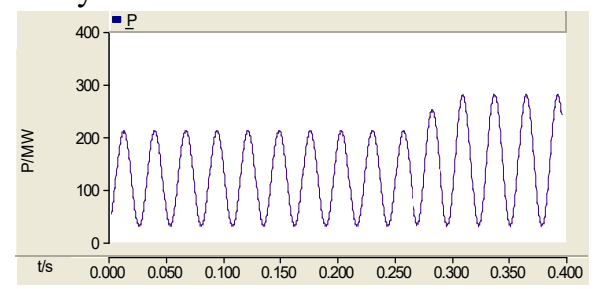

(a) active power waveform

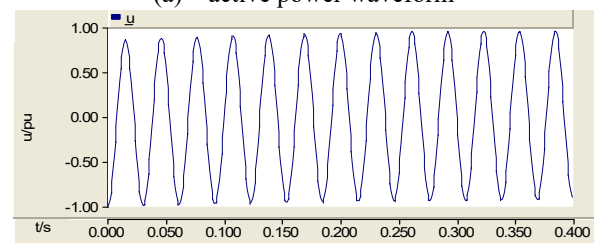

(b) terminal voltage waveform

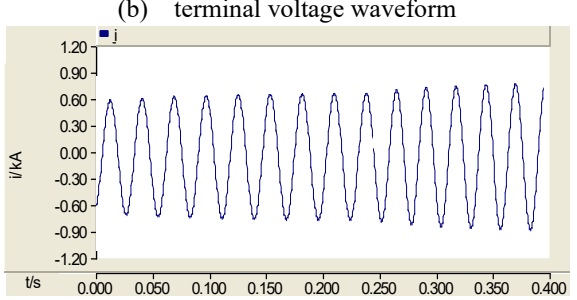

(c) output current waveform

Fig13. Waveforms of $\mathrm{V} / \mathrm{F}$ controlled inverter when single phase grounding short circuit fault occurred

According to the simulation analysis, the fault characteristic data under $\mathrm{V} / \mathrm{F}$ control strategy are shown in Table 2.

Table2. Normal and fault data underV/F controlled inverter

\begin{tabular}{|c|c|c|c|}
\hline & $\begin{array}{c}\mathrm{P} \\
(\mathrm{MW})\end{array}$ & $\begin{array}{c}\mathrm{U} \\
(\mathrm{pu})\end{array}$ & $\begin{array}{c}\mathrm{I} \\
(\mathrm{kA})\end{array}$ \\
\hline $\begin{array}{c}\text { Normal } \\
\text { operation }\end{array}$ & 0.21 & 1.0 & 0.60 \\
\hline $\begin{array}{c}\text { Three-phase } \\
\text { short circuit }\end{array}$ & 0.36 & 1.01 & 1.04 \\
\hline $\begin{array}{c}\text { Two-phase } \\
\text { short circuit }\end{array}$ & 0.30 & 1.01 & 1.01 \\
\hline $\begin{array}{c}\text { Two-phase } \\
\text { grounding } \\
\text { short circuit }\end{array}$ & 0.31 & 1.01 & 1.02 \\
\hline $\begin{array}{c}\text { Single-phase } \\
\text { grounding } \\
\text { short circuit }\end{array}$ & 0.30 & 1.01 & 1.01 \\
\hline
\end{tabular}

The simulation experiment shows that that IIDG under $\mathrm{V} / \mathrm{F}$ control strategy can play a better role, so that the terminal voltage of IIDG can be basically kept constant when the system has a short-circuit fault. In addition, due to the upper limit of active power in this control strategy, and its terminal voltage is stable around the rated voltage, the fault current of IIDG has little difference.

\section{Conclusions}

Firstly, the model of IIDG is simplified, and the mathematical models of IIDG are established under P/Q control strategy and $\mathrm{V} / \mathrm{F}$ control strategy. Then, the simulation model of IIDG is established by power system transient simulation software PSCAD. The fault characteristics of IIDG under P/Q control strategy and V/F control strategy are analyzed respectively. Through the above analysis, the following conclusions are obtained:

(1) IIDG under P/Q control strategy has the lowest terminal voltage when three-phase short circuit occurs, and the highest terminal voltage when single-phase ground short-circuit occurs; the minimum fault current occurs when two-phase short-circuit occurs, and the maximum fault current occurs when single-phase ground short-circuit occurs. The positive sequence impedance of IIDG is greater than its zero sequence impedance. The controlled voltage source after reactance can be equivalent to IIDG. The controlled condition is that the output power of IIDG is constant, and the constraint condition is that the outlet current value of IIDG is less than 2 times of its rated current value.

(2) IIDG under V/F control strategy, the fault voltage of IIDG is basically maintained near the rated voltage when the fault point is far away from the outlet of IIDG. Since the upper limit of active power is set in V/F control strategy, the difference of fault current at IIDG outlet is not obvious when various short circuit faults occur. In this case, the controlled current source after reactance can be used to equivalent to IIDG. Obviously, the controlled condition is that the terminal voltage remains constant, while the constraint condition is that the outlet current value of IIDG is less than 2 times of its rated current value.

\section{References}

1. B. Zhao, C.S. Wang, J.H. Zhou, AEPS, 38, 125135(2014)

2. G. Pepermans, J. Driesen, D. Haeseldonckx, Energy Policy, 33, 787-798(2005)

3. X. Yang, X. Guo, H.Y. Zang, Journal of Electrical Engineer, 27, 63-68(2012)

4. C.H. Liang, X.Z. Duan, AEPS, 25, 53-56(2001)

5. C.H. Cheng, JGSCASS, 113-118(2009)

6. L.C. Wang, H.L. Gao, PCMPS, 2, (2017)

7. V. Sridhar, S. Umashankar, RSER,78(2017)

8. E. Gnani, M. Visciarelli, A. Gnudi. Solid State Electronics (2019) 